\title{
El cine de no ficción en el Ecuador: horizontes
}

\section{The nonfiction cinema in Ecuador: horizons}

Carlos Ernesto Gavilondo Rodríguez

Universidad Politécnica Salesiana, Ecuador

María Belén Mercado Cevallos

Universidad Politécnica Salesiana, Ecuador

Autor para correspondencia: gavilondocarlos@gmail.com,mmercadoc@est.ups.edu.ec

Fecha de recepción: 20 de Diciembre de 2016 - Fecha de aceptación: 10 de Febrero de 2017

\section{Resumen}

El artículo expone los resultados de una investigación que centra su objeto de estudio en el cine de no ficción ecuatoriano. Se indaga, desde una perspectiva cualitativa de tipo exploratorio descriptivo, la producción y situación actual de la cinematografía ecuatoriana haciendo especial énfasis en el cine documental en el período comprendido entre los años 2015-2016. Los principales resultados apuntan a que la producción de obras de no ficción en el Ecuador va en aumento y que propone convertirse en un cine de referencia para Latinoamérica. Como parte de las conclusiones se encontró que esta manifestación artística requiere, necesariamente, del apoyo gubernamental el cual, en el período estudiado, es prácticamente nulo.

Palabras claves: Cine; no ficción; documental; cinematografía; Ecuador

\begin{abstract}
The article exposes the results of an investigation that focuses its object of study in the nonfiction cinema of Ecuador. From a qualitative perspective of descriptive exploratory type, the production and current situation of Ecuadorian cinematography is investigated with special emphasis on documentary filmmaking in the period between 2015-2016. The main results indicate that the production of non-fiction in Ecuador is increasing and that it proposes to become a cinema of reference for Latin America. As part of the conclusions, it was found that this artistic manifestation necessarily requires government support which, in the period studied, is practically nil.
\end{abstract}

Key words: Cinema; non-fiction; documentary; cinematography; Ecuador 


\section{Introducción}

El acercamiento al tema objeto de investigación, que se ha definido como los usos y horizontes del cine de no ficción ecuatoriano en el periodo 2015-2016, se inicia desde la concepción epistemológica del término cinematografía que se concibe, desde su raíz griega, por la unión de dos palabras. Estas son kine y grafos, la primera relacionada con el movimiento y la segunda con la imagen. El tema de la investigación tiene su génesis en la necesidad de conocer el estado actual del cine de no ficción ecuatoriano. Investigaciones previas evidencian un crecimiento desde lo industrial y tecnológico en la cinematografía ecuatoriana, pero este género pudiera afirmarse que aún no despega. El cine ecuatoriano, y en particular el de no ficción, puede considerarse que está en desarrollo en tanto se encuentra en algunas muestras de cine a nivel nacional e internacional. La temática de la realización audiovisual de no ficción, en el Ecuador, a juicio de la investigación, no tiene una presencia significativa dentro de la producción científica y académica del país. Investigadores ecuatorianos como Christian León y Santiago Rubín se han acercado al tema del audiovisual de no ficción teniendo, entre sus principales líneas de investigación, la diversidad temática, enfoques y modelos utilizados. Sus excelentes y profundas miradas a este género se centran en estudios realizados y publicados entre los años 2005-2015.

Para el año 2014 Santiago Rubín, en investigación realizada acerca del cine documental ecuatoriano, enuncia que:

La ecuatoriana es, sin duda, una de las cinematografías menos conocidas del hemisferio sur americano. El cine de Ecuador, hasta hace poco prácticamente invisible fuera de sus fronteras, ha vivido un lento proceso de expansión tanto industrial como tecnológica a lo largo de las últimas décadas. (Rubín de Selis, 2014, p. 33)

Si se toman estos referentes la investigación, entonces, se justifica y valida teniendo en cuenta que intenta esbozar el panorama del cine documental ecuatoriano en la actualidad. Centra su estudio en el período 2015-2016. Se pretende revisar aspectos ya estudiados referidos a temáticas, enfoques y modelos empleados en este género para evidenciar su perspectiva actual. Surge el cuestionamiento, entonces, de por qué el género no progresa, en su totalidad, si investigaciones previas concluyen afirmando que el cine de no ficción ecuatoriano vive un momento de crecimiento, tanto industrial como tecnológico. Para ser consecuentes con la pregunta problema se precisa, como objetivo general, determinar los niveles de visibilidad del cine no ficción ecuatoriano en el periodo 2015 - 2016 y, como objetivos específicos, sistematizar, desde el acercamiento teórico, las temáticas abordadas, los enfoques y modelos utilizados en la producción del cine de no ficción ecuatoriano y valorar, partiendo del estado actual de la producción del cine de no ficción ecuatoriano, sus representaciones futuras. Teniendo como sustento la pregunta problema se decide el empleo de la matriz de investigación cualitativa de tipo exploratorio-descriptivo los cuales, muchos autores e investigadores, han conceptualizado como experimentales. Entre los resultados de la investigación destaca el hecho que el cine ecuatoriano, en estos momentos, se está desarrollando a muy buen nivel. Tanto la actuación como la producción han subido sus estándares por lo que se considera un cine, de ficción y no ficción, competente ante los niveles del cine latinoamericano. Aún no se ha potenciado la narrativa de las historias, o sea, se adolece del saber contarlas y de contar historias interesantes, así como acabar de entender qué es lo que el público realmente necesita. Dos conclusiones a tener en cuenta son, primero, que el cine de no ficción ecuatoriano tiene que abrir 
su espectro a temáticas más generales en tanto, si se continúa haciendo un cine documental a lo interior de las comunidades y las problemáticas regionales, no se lograrán niveles altos de inserción en el mercado del audiovisual a nivel internacional. Como segundo aspecto a tener en cuenta, como conclusión es que el Instituto Ecuatoriano de Propiedad Intelectual debe sistematizar el trabajo y ocuparse, realmente, del tema de la regulación y legalización del sector audiovisual. Solo así podría evolucionar y tener mayor presencia el cine de no ficción ecuatoriano.

\section{Cinematografía ecuatoriana: una introspectiva necesaria.}

En el cine ecuatoriano no sucede lo que en la cinematografía europea o parte de la hispanoamericana y latinoamericana donde se expone un amplio recorrido. Se habla de un cine ecuatoriano a partir de 1970. Esto no significa que no existió con antelación pero fueron obras muy escasas que, por lo general, se inclinaron a la documentalista y fueron realizadas por directores foráneos. Hasta ese entonces la producción de obras de ficción fue muy baja y se repetía el estilo melodramático del cine mexicano. La primera generación de cineastas locales se formó en Rusia y México y comenzaron su trabajo en el género documental con énfasis en temas de identidad nacional. En ese sentido, Luzuriaga (2013), manifiesta que:

El hecho que la primera generación de cineastas ecuatorianos haya empezado filmando películas cortas y documentales no es casual, se corresponde a la etapa primigenia por la que cursaron todas las cinematografías, aprendiendo a armar el discurso cinematográfico desde la brevedad del cine de corta duración, y reconociendo que el país no disponía de una tradición dramatúrgica y teatral a partir de cuya experiencia poder construir la ficción. (p.76)

El cine se reconoce como un medio excelente para representar la identidad y, por lo general, el espectador responde a esto. Por situaciones, quizá aún desconocidas, el ecuatoriano prefiere recrearse con una producción norteamericana en detrimento de la producción nacional pero es válido reconocer que existe en Latinoamérica y en Ecuador en particular un potencial que aún falta por explorar. Esa pude ser la base de la percepción del ecuatoriano acerca del cine local y que, por supuesto, lastra la labor del cineasta ecuatoriano. Sigue el cuestionamiento de por qué el cine ecuatoriano no despega y una de las cosas que se afirma que sucede es lo referido a la publicidad que aún no es suficiente y, por supuesto, marca índices de aceptación del cine ecuatoriano muy por debajo de otras cinematografías a nivel mundial. Puede pensarse, entonces, que el cine latinoamericano y en especial el ecuatoriano están aún muy lejos de poder integrarse a esa gran maquinaria de producción-distribución pero, en ese sentido, Cordero (2012) deja muy bien definida su posición al comentar:

Sigo haciendo cine en mi país porque creo que no es imposible que una película latina entre al mercado mundial; más aún, creo que es posible generar un mercado latinoamericano unificado y fuerte. Solo es cosa de tiempo para que esto suceda y todos salgamos favorecidos. (p.17)

Referido a este tema se observan algunas contradicciones en las que la investigación indagará, se ve a un Sebastián Cordero, destacado cineasta ecuatoriano considerado el máximo exponente del gremio nacional, apelando por la institucionalización de la cinematografía ecuatoriana y al papel que, desde su apreciación, debe asumir el gobierno por el desarrollo del 
cine local. Por otro lado aparecen criterios de expertos que reflejan que la prosperidad del cine ecuatoriano la marcó, precisamente, Sebastián Cordero con su obra Rata, ratones, rateros en el año 1999 y fuentes oficiales destacan que con la aparición de la ley de cine del Ecuador el gobierno invierte un promedio de un millón de dólares anuales en la producción cinematográfica nacional. Analizado esto pudiera pensarse en una concientización gubernamental en cuanto a la cinematografía se refiere pero, si se sigue el discurso y reflexión del Sebastián, se aprecia una continuidad en la polémica en tanto en su artículo, desde donde hace un cuestionamiento de la calidad del cine ecuatoriano, exterioriza:

Producir cine en el Ecuador es casi un milagro. Con un promedio de un largometraje cada tres años, hablar de una industria cinematográfica ecuatoriana es algo aún muy lejano. No existe ningún tipo de ayuda gubernamental para la producción, lo que dificulta mucho las cosas, pues el cine local no ha podido todavía ser rentable. (Cordero, 2012, p. 19)

El experto en audiovisuales, el ecuatoriano Christian León, refiriéndose a la cinematografía ecuatoriana expresó que “es una cinematografía absolutamente emergente, en el sentido que no tenemos tradición“ (León, 2005, p. 5). Por otro lado, la directora de cine ecuatoriana Vivian Cordero, como se citó en González Rentería (2015), señalo que "hay que seguir moviendo el cine nacional para que justamente el público se siga acostumbrando y vaya a ver las películas ecuatorianas" (p. 133) y el investigador Santiago Rubín de Celis, también ecuatoriano, expresa:

El cine de Ecuador, hasta hace poco prácticamente invisible fuera de sus fronteras, ha vivido un lento proceso de expansión tanto industrial como tecnológica a lo largo de las últimas décadas (...) y en términos de visibilidad es muy posible que el fenómeno contemporáneo más destacable sea la no ficción. (Rubín de Selis, 2014, p.33-34)

Albancés (2014) se refiere al audiovisual ecuatoriano en sentido general más allá del género y, como se citó en Palacio Ospina \& Gavilondo (2016), explica que “desde los años 2000 el audiovisual ecuatoriano se centró en la revisión de algunas de las páginas de la historia y esto ha llevado a producciones que han marcado la existencia de un audiovisual de contenido en Ecuador" (p. 29). A juicio de la investigación lo planteado por Albancés puede tener su referente en la consolidación de Quito, Guayaquil y Cenca como sedes para la muestra de cine documental en Ecuador a partir del año 2002. Estas muestras no se limitaron solo a las salas de cine establecidas, se expandieron más allá, llegando a centros de exhibición alternativos. Para ese entonces Ecuador se convirtió en un espacio para la llegada de cineastas que, en muchas ocasiones, se acompañaban de su equipo de trabajo. Esto trajo consigo que las audiencias se hicieran más receptivas a lo local cuestión que, al decir de Sebastián Cordero, no está del todo resuelta y, Segú él supone un retraso en el despegue del cine ecuatoriano. Este impulso a la visibilidad del cine de no ficción ecuatoriano y a su relación con otro cine se potenció, al decir de Franco Varas (2016), "por la creación del Festival Internacional de Cine Documental Encuentros del Otro Cine, conocido por las siglas EDOC, el cual alcanzó niveles insospechados" (Franco Varas, 2016, p. 1). Este festival, como se citó en http: //www.eltelegrafo.com.ec, en su edición del 23 de Mayo de 2016, trajo al documental para quedarse en las frecuentes funciones de cine en el país. "Con ello se pone a Ecuador en el mapa de los festivales de cine a escala mundial y se permite a los documentalistas nacionales perfeccionarse ante el público" (Franco Varas, 2016, p. 1). Esta situación, a juicio de la investigación es, por supuesto, muy positiva. 


\section{Metodología}

La investigación, cuyas deducciones son la esencia del presente artículo, persigue conocer el estado actual del cine de no ficción ecuatoriano y pretende revisar aspectos ya estudiados referidos a temáticas, enfoques y modelos empleados en este género para evidenciar la perspectiva actual. Se toma, como punto de partida, el cuestionamiento de por qué el género no progresa, en su totalidad. Como objetivo general se precisa determinar los niveles de visibilidad del cine no ficción ecuatoriano en el periodo 2015 - 2016 y, como objetivos específicos, sistematizar, desde el acercamiento teórico, las temáticas abordadas, los enfoques y modelos utilizados en la producción del cine de no ficción ecuatoriano y valorar, partiendo del estado actual de la producción del cine de no ficción ecuatoriano, sus representaciones futuras. El proceso de acercamiento al objeto de investigación se realizó apoyado, fundamentalmente, en técnicas tales como: revisión bibliográfica documental y la entrevista a expertos. La matriz de investigación empleada se reconoce como cualitativa de tipo descriptivo exploratorio. El empleo de estas técnicas validó los resultados obtenidos.

\section{Resultados}

Comienza este apartado con un planteamiento de Stuart Hall (1997), como se citó en León (2007) donde expresa que tal parecería que estamos frente a ese momento irreductible en que el significado empieza a rodar y puede ser flexionado hacia nuevas direcciones y define, a ese lapso como:

Las palabras y las imágenes llevan connotaciones sobre las que nadie tiene control completo y esos significados marginales o sumergidos vienen a la superficie permitiendo que se construyan diferentes interpretaciones, que diferentes cosas se muestren y digan. (León, 2007, p. 89)

Se considera al documental un soporte que sirve para revisar el modo en que la historia se manifiesta y se transmite o, lo que es lo mismo, el modo en que nuestra memoria se constituye entre olvidos y clichés pero el tratamiento al documental ecuatoriano dicta mucho de lo anterior en tanto, aunque en estos momentos se está desarrollando a muy buen nivel y la actuación y la producción han subido sus estándares por lo que puede considerarse un cine, de ficción y no ficción, competente ante los niveles del cine latinoamericano, aún no se ha potenciado la narrativa de las historias, o sea, se adolece del saber contarlas y de contar historias interesantes, así como acabar de entender qué es lo que el público realmente necesita. Hay que revisar si nuestros escritores y literatos tienes que comenzar a incursionar en el tema de la cinematografía porque realmente el director y el productor no son contadores de historia. No es cuestión, solo, de dirigir o producir es cuestión, además, de escribir la historia, de saber contar y de eso aun adolece la cinematografía ecuatoriana no solo la de no ficción, también la de ficción. Se vio, por mucho tiempo, un cine ecuatoriano de la droga, la familia, el dinero, pero ya hay una nueva generación que está comenzando y entiende que hay que hacer películas no solamente para el director, sino que hay que hacer un cine que sirva y potencie la creación. Dentro de la cinematografía ecuatoriana se puede afirmar que es, el documental, el que mejor y mayor perspectiva tiene de desarrollo y así se evidencia en estos tiempos. Las investigaciones que sirvieron como punto de partida para indagar en este objeto de estudio constituyeron un referente del cine de no ficción hasta el año 2015, referente que evidenció una decadencia del documental pero, los resultados de esta investigación, testifican el renacer del género. 


\section{Conclusiones}

Si bien la documentalistica ecuatoriana no ha podido aun trascender a lo internacional si se cuenta ya con obras de gran nivel y con una producción nacional de prestigio. Hay que tener en cuenta dos aspectos fundamentales que conspiran contra la documentalistica ecuatoriana y estas son: que el cine de no ficción ecuatoriano tiene que abrir su espectro a temáticas más generales en tanto, si se continúa haciendo un cine documental a lo interior de las comunidades y las problemáticas regionales, no se lograrán niveles altos de inserción en el mercado del audiovisual a nivel internacional. Como segundo aspecto a tener en cuenta, como conclusión, es que el Instituto Ecuatoriano de Propiedad Intelectual debe sistematizar el trabajo y ocuparse, realmente, del tema de la regulación y legalización del sector audiovisual. Solo así podría evolucionar y tener mayor presencia el cine de no ficción ecuatoriano.

\section{Bibliografía}

Cordero, S. (2012). Ecuador y América Latina. ¿Es su cine escaso y de mala calidad? Quito, Ecuador. Recuperado el 16 de Agosto de 2016

Franco Varas, W. (23 de Mayo de 2016). Festival EDOC: Plataforma para un género que prospera en Ecuador. El Telégrafo., pág. 1. Recuperado el 4 de Diciembre de 2016, de http://www.eltelegrafo.com.ec/noticias/carton-piedra/34/festival-edoc-plataforma-para-ungenero-que-prospera-en-ecuador

González Rentería, V. (2015). El cine emergente en Ecuador. Una mirada a su evolución. En M. I. Larrea (Ed.), Comunicación y periodismo: cinco versiones de la historia. (Vol. V, págs. 111-143). La Laguna, Tenerife, España: Sociedad Latina de Comunicación Social. Doi: 10.4185/cac99

León, C. (Julio de 2005). Racismo, políticas de la identidad y construcción de "otredades" en el cine ecuatoriano. Revista Chilena de Antropología Visual., 91-100. Recuperado el 16 de Agosto de 2016, de http://www.antropologiavisual.cl/

León, C. (Diciembre de 2007). Crítica poscolonial, performatividad cinematográfica y resistencia indígena. Apuntes para el análisis de la crisis del documental indigenista en Ecuador. Revista Chilena de Antropología Visual (10), 85-108. Recuperado el 15 de Noviembre de 2016, de http://www.rchav.cl/2007_10_art04_leon.html\#Layer1

Luzuriaga, C. (Febrero de 2013). Antecedentes, inicios y problemas del cine histórico en el Ecuador: apuntes para un estudio crítico. Ensayos, 74-80. Recuperado el 19 de Octubre de 2016, de https://www.revista.uclm.es/index.php/ensayos

Moscoso, O. (2 de Noviembre de 2016). El documental en el Ecuador. (B. Mercado, Entrevistador) Guayaquil, Ecuador.

Palacio Ospina, J. M., \& Gavilondo, C. (26 de Septiembre de 2016). La creación de productos comunicativos audiovisuales. Una mirada al audiovisual ecuatoriano. Innova Research Journal, 1(9), 26-38. Recuperado el 23 de Noviembre de 2016, de http://www.journaluidegye.com/magazine/index.php/innova/author/submission/49

Rubín de Selis, S. (Septiembre de 2014). El cine documental ecuatoriano contemporáneo. Recuperado el 19 de Septiembre de 2016, de Dialnet: www.doc.ubi.pt 